momentum due to the satellite system and the rotation of the planet taken together correspond to the angular momentum of the matter which was sufficiently near a planetary nucleus to be retained in its neighbourhood by gravitation, or in the course of time has been caught in encounters. The direction of rotation should therefore be the same as that of the system as a whole, and thus that of the planetary orbits; the few exceptions to this rule are readily explained as accidental deviations due to local conditions (the Uranus system and the satellite of Neptune) or capture in recent times (Jupiter VIII and IX, Saturn IX). The strong correlation between the angular momentum of rotation of the planet and the mass of the satellite system is readily understood. Apparently singular objects like the satellites of Mars may be understood without making the assumption that these bodies have originated directly out of the mass of the planet.

The rings of Saturn are perhaps best explained directly as small particles formed by condensation inside Roche's limit for the planet in question. The extremely flat formation is explained partly by the condensation of the particles out of a gaseous cloud, which causes the particles to follow originally nearly circular motions with low inclinations, but mainly by the influence of mild collisions between neighbouring particles, as explained by Jeffreys ${ }^{10}$ and on somewhat different lines by myself in a recent paper ${ }^{11}$.

The corpuscles of the zodiacal light have possibly been formed fairly recently ${ }^{12}$ out of the last remnants, perhaps reformed by volatilisation, of the nebulous cloud surrounding the sun.

Finally we must mention the probable status of the meteorites. Their division into, roughly, two widely different kinds, stony and iron meteorites, suggests that they can scarcely be considered exclusively as direct condensation products. We may perhaps get a general explanation of their physical nature, as well as of their motions, which obviously differ very much from the circular orbits in the invariable plane of the solar system, by assuming that they are, generally speaking, remnants of larger bodies, shattered by violent encounters in the manner which has been considered above. Like the planets, these larger bodies have therefore formed to a great extent by accumulation of smaller particles. We can then assume, in conformity with the views put forward by geophysicists ${ }^{13}$, that a certain sedimentation of the various minerals has taken place at a fairly high temperature in the bodies in question before their disruption. Those meteorites which did not originally belong to our system have probably emanated from analogous systems in other regions of the Milky Way, forming showers of particles traversing the voids of interstellar space much like the stars themselves. In regard to their origin they are, according to our point of view, largely a sort of by-product in the process of formation of planetary systems.

${ }^{1}$ Mon. Not. Roy. Ast. Soc., in press.

2 "The Internal Comstitution of the Stars" p. 371 ; 1926.

${ }^{3}$ Phys. Rev., 8, 149; 1916. Proc. U. S. Nat. Acad., 3, 141; 1917.

Astrophys. J., 69, 7 ; 1929

KK. Sven. Vetenskap., Handl., 3, 13, No. 2; 1934. (Upsala Medde lande, No. 58.)

"The Earth", p. $250 ; 1924$

Mon. Not. Roy. Ast. Soc., 94, 231 ; 1934

${ }^{8}$ Cf. Schoenberg and Jung, Astron.' Nachr., 247, 413 (1933).

${ }^{\circ}$ Cf. Struve, Elvey and Keenan, Astrophys., $J ., 77,274 ; 1934$

${ }^{10}$ Mon. Not. Roy. Ast. Soc., $7 \mathrm{r}, 91 ; 1916$.

${ }^{11}$ loc. cit.

${ }^{19}$ Cf. H. Jeffreys, loc. cit.

13 Cf. G. v. Hevesy, "Chemical Analysis by X-Rays and its Applications". (Cornell University Publ. 1932.)

\title{
Deep Diving and Under-Water Rescue
}

CIR ROBERT DAVIS delivered the Thomas $S_{\text {Gray Memorial Lectures for } 1934 \text { of the Royal }}$ Society of Arts, and spoke on deep diving and under-water rescue. The lectures have now been published; they form a valuable study of the development of apparatus and technique, admirably illustrated and lightened by comments and anecdotes arising out of the author's lifelong experience of the subject.

Divers have always wanted to get a little deeper, but the particular obstacle to be overcome has varied in successive generations. At first it was the matter of air supply, when the eighteenth century inventor and his victims "discovered by bitter experience that the leathern bellows, which worked so admirably when blowing an organ or smith's forge, were quite incapable of forcing air down to a diver" working at more than two or three feet deep. Later, when the introduction of metal air pumps enabled a supply to be delivered at high pressure, came the mysterious, crippling, 'diver's palsy' which we now call compressed air illness. Later still, when physiologists had elucidated the cause of this trouble and devised methods of slow decompression to avert it, came the economic difficulty that at depths of thirty fathoms and upwards, so much of the diver's time under water had to be used in decompression that only a fraction remained available for useful and paying work. Now the invention of the Davis Submerged Decompression Chamber (see Nature, August 29, 1931) has eased this situation and made salvage work in the rubber dress a practical procedure up to 300 feet depth; and there for the moment we rest.

The deep diver of to-day receives a measured supply of clean air from steam compressors. An 
injector circulates the air from his helmet through an absorbent which removes carbon dioxide as fast as his breathing produces it. $\mathrm{He}$ is in constant telephonic communication with the organisation in the salvage ship above, which not only controls his decompression but also, through the agency of such devices as grabs and pneumatic tools, takes over an increasing share of the manual work to be done on the bottom. Expensive plant, once started, should run continuously, hence a succession of fresh divers is required who have to subordinate their procedure to the common plan of the team. The famous divers of the past, some of whose feats Sir Robert described, worked almost singlehanded in far greater danger and discomfort ; only the fittest mentally and physically could attempt the deeper work and these few acquired outstanding skill and experience. It may be that we shall not see their like again.

More than fifty years ago one of these men, Alexander Lambert, struggled through 1,000 feet of the wrecked and flooded Severn tunnel in complete darkness to close an iron door and enable the water to be pumped out. As it was impossible to drag such a great length of air pipe behind him, he used H. A. Fleuss's newly invented self-contained diving-dress, putting it on for the first time that day. This was the prototype of the now familiar type of breathing apparatus in which carbon dioxide is removed from the expired air by passing it over caustic alkali, and the oxygen consumed by the user is replaced from a high pressure cylinder. This system is in use in mine rescue and fire brigade smoke helmet apparatus all over the world to-day, but has perhaps been carried to the highest point of development and portability in the compact Davis Submarine Escape Apparatus, which now provides each member of the crew of all British (and many foreign) submarines with the means of breathing in suffocating gases or under water until the escape hatches can be opened, when it will waft him gently to the surface and support him there until help arrives.

\section{The Future of Tropical Australia \\ By Dr. L. DUDLEY STAMP}

$\mathrm{F}^{\mathrm{o}}$ OR more than a century the British Government, the colony of South Australia, and the Australian Commonwealth have attempted to develop the half million square miles contained within the Northern Territory. More than $£ 17,000,000$ has been expended in the effort, yet to-day the entire population consists of some 3,000 whites, 800 yellow persons, 900 half-castes and probably 20,000 aboriginals. The mining and cattle industries, once promising, have declined. The same state of affairs is found in the tropical parts of Western Australia, where the total nonaboriginal population is less than 2,000. It is only on the patches of richer soil along the coast of Queensland that the population of tropical Australia is relatively flourishing and increasing.

A few years ago, Prof. Griffith Taylor ${ }^{1}$ was almost alone in declaring that only three per cent of tropical Australia-entirely in the coastal belt of Queensland with its well-distributed rainfallwas suitable for tropical agriculture and consequent close settlement. His views are gradually becoming generally accepted, but there is still a wide divergence of opinion on the reasons for the lack of settlement. Sir James Barrett in a recent article ${ }^{2}$ says, "It is generally assumed that there is a medical, or rather physiological, reason for failure to settle parts of tropical Australia. So far as investigation goes there is nothing of the kind. The failure to settle some parts of tropical Australia and the successful settlement of other portions of the tropics is solely economic." In his consideration, he rightly divides tropical Australia into four regions: (1) the coastal districts of Queensland with good soil and abundant rainfall ; (2) the western portion of Queensland suitable for grazing; (3) the Northern Territory; and (4) the northern portion of Western Australia similar in character to (3). He shows that in the last ten years the annual increase of population in tropical Queensland has been 2 per cent per annum, against 1.5 per cent for non-tropical Australia. He finds that birthrate, infantile and general death rates in tropical Queensland compare favourably with those of many non-tropical countries, are better than those of metropolitan non-tropical Australia and are little if at all inferior to those of Australia as a whole.

It is, as Sir James argues, unfair to consider the vital statistics for regions (3) and (4) because of the small size of the sample. Economic nationalism and State socialism are blamed for preventing more rapid development of tropical Australia- "it is certain that it is not the effect of the climate on Anglo-Saxons". On the other hand, R. W. Cilento, director of Australian tropical hygiene, considers that the Commonwealth is evolving a new type of person--the North Queenslanderwho "moves slowly and conserves his muscular heat-producing energy in every possible way", thus agreeing with results of experiments carried out by American physiologists recently* The 